\title{
EARTH OBSERVATION ACTIVITIES AND FUTURE PERSPECTIVES IN EGYPT
}

\author{
I. Abou El-Magd ${ }^{1 *}$ \\ ${ }^{1}$ Department of Environmental Studies, National Authority for Remote Sensing and Space Sciences (NARSS), Cairo, Egypt - \\ imagd@narss.sci.eg
}

Key Words: Remote Sensing, Sustainable Development, Capacity Development, Strategy, Egypt

\begin{abstract}
:
Egypt was one of the first developing countries in Africa that used earth observation and remote sensing in various applications since 1970s. It has grown up in the last decades to build its own capacity in space science and technology that ended up by launching earth observation satellites. At the same time Egypt continued to develop the capacity in EO applications and contribute to the national development plans. In this domain NARSS, the governmental research institute that lead the EO and space applications has completed many research and development projects in EO applications in mineral resources exploration, coastal and marine resources, air quality, water resources management, food security, etc. This was via operational projects with the stakeholders and users to ensure sustainability and operation of the services. For example, NARSS has developed an operational system to monitor the national crop rice using EO information that capable to provide the actual land planted with rice and predict the yield. The system has enabled to provide recommendations for other plots of land that suitable for rice plantation. In the area of environmental hazards, many projects on the flash floods and the vulnerability to flash flood hazards were developed providing decision makers with vulnerability maps and Atlases on national level. Further details on the EO activities and future plans at NARSS, Egypt will be presented in this paper.
\end{abstract}

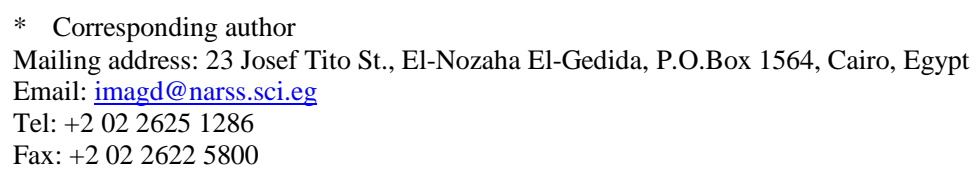




\section{INTRODUCTION}

Remote sensing is defined in its broadest sense, including data acquisition by hand-held and fixed ground-based sensors, such as camera traps and acoustic recorders, and sensors on airplanes and satellites. Remote sensing technologies from all sources provide powerful tools for understanding the earth status and forecast information about each of the Earth systems and the interaction between them, and provide precise information for informed decisions.

Space technology and remote sensing application have been developed since the middle of the last century with an increased space industry since the first launch of Russian satellite Sputnik-1 in 1957. Advancement of the technology was fast since that time with microsatellites, nano satellites and cube sat satellite. The rapid development of the technology and launch of the remote sensing satellites played key role in the availability of the information for earth monitoring, economic development and disaster risk reduction. Remote sensing has enormous potential as to provide information on the state of, and pressures on, biological diversity and ecosystem services, at multiple spatial and temporal scales.

\section{HISTORICAL BACKGROUND}

Egypt was one of the first countries in Africa and Middle East to use remote sensing. The activity of remote sensing in Egypt began early in 1971 through an American-Egyptian joint project that established a remote sensing center under the umbrella of the Academy of Scientific research and technology that supposed to promote and use the satellite data of Landsat-1 satellite that launched in 1972. The use of Landsat-1 data enabled to develop national capacity and implement projects and applications of natural resources and environment.

The development of the remote sensing center and show cases of applications and projects provided motivation to the government to establish governmental research institute dedicated to space technology and remote sensing applications. The is the national authority for remote sensing and space sciences, which mandated to develop the national capacity in these fields, strengthen the technology and widen the applications.

\section{CURRENT VISION}

The vision is to play key role in space technology and remote sensing applications in the region and contribute to the global arena. This required putting national strategic goals and roadmap for implementation. The key principles of this strategy are:

- Meeting the user's needs to harness the potential benefits of remote sensing and space science and technology in addressing social and economic opportunities and challenges in the country

- Improving the economy and quality of life using space applications to contribute in the socioeconomic development.
- Protect our environment, ecosystems and manage the natural resources

- Provide services and products derived from space to meet the basic information needs of the market.

To achieve these goals and strengthen the national capacity, it was essential to develop the infrastructures. Egyptsat-1 "an earth observation satellite" was launched in April 2007 with medium resolution of 7.8 meter. At the same time, the ground receiving station was modulated to receive data from other global satellites such as SPOT4. A second earth observation satellite was launched in 2014 with a plan for another series of satellites. This enabled for stream data acquisition for earth monitoring and contributing to the socio-economic development.

Moreover, NARSS possess an airplane that equipped with airborne remote sensing systems of RGB camera; and recently it is equipped with advanced sensors of LiDAR and Hyperpsectral sensors.

\section{RESEARCH PROJECTS AND OPERATIONAL SYSTEMS}

Sustainable development is one of the major problems all over the world particularly developing countries such as Egypt. According to the classical conception, sustainable development consists of social, economical and environmental components. For better environmental sustainability and development, national indicators are required to monitor and assess the sustainable development that aligned with preserving the environment. Therefore, environmental indicators are important tools to integrate multiple data sets to generate valuable information to decision makers and the public. This is of great importance to sustain our environment and natural resources and combat environmental degradation.

In July 2016, Egypt has adopted an approach that is characterized by a high level of ambition, firm commitment and dynamic innovation towards tackling this transformative SDG agenda- In alignment with the global 2030 Agenda, Egypt launched in March 2015 its strategy for sustainable development "Egypt's Vision 2030". The Egyptian forwardlooking strategy is unprecedented in its scope and significance at the national level. It spans over the three dimensions of sustainable development, namely; economic, social and environmental dimensions, and outlines the broader principles which will guide Egypt in pursuing its developmental goals. The overarching aim of the strategy is for Egypt to possess a competitive, balanced and diversified economy, dependent on innovation and knowledge, based on justice, social integrity and participation, in a balanced and diversified ecological collaboration system, investing the ingenuity of place and human capital to achieve sustainable development and to improve Egyptians' quality of life, in a state- driven process, with the full participation of all relevant stakeholders (Ministry of International Cooperation, 2016)

Egypt has a vision to comply with the 17 global SD Goals to achieve high economic growth and environmental 
sustainability by 2030 . To meet these challenges the Egyptian Government has set up some of the major projects or priority areas that could achieve the national and global sustainable development goals (SDGs) in the three major dimensions of economic, social and environment. The major priority areas include set of mega projects and some strategic projects. It is anticipated that this strategy will foster economy and improve social status and sustain the environment. Examples of these two types of projects could be summarized as follows:

1. Agriculture sector - land reclamation for one million Acre

2. Logistics - Suez Canal Area Development Project

3. Urban planning - Building one million social housing units

4. Creating new development axes:

a. The establishment of a number of storage and logistics centers in Damietta

b. The development of the Golden Triangle on the Red Sea and eastern desert

c. The development of the North West Coast

5. Tourism Sector - develop new tourism areas to attract more tourism

6. Mining Sector - explore mineral resources and develop mining activities

The implementation of these projects require regular information and data that support the planners and decision makers to develop the action plan for implementing these projects. Furthermore, the spatial analysis of this information will enable for wider perspective in the development plan and ensure lower risk or vulnerability. It is anticipated that remote sensing and earth observation tools will significantly contribute in planning and implementing these projects and achieving the proposed national SDGs. Later in this report, there will be an example of using remotely sensed data and geospatial information analysis in similar projects in Egypt together with highlight on the new trends of remote sensing in achieving the SDGs.

The challenges were how much remote sensing applications could be functioned to support decision makers in sustainable development. In this section few examples of applications and operational services derived from remotely sensed data. The availability of meteorological station that receives daily data from NOAA satellites enabled to retrieve daily and monthly services. Two main services are generated daily and averaged to monthly. Surface temperature and vegetation cover (NDVI - Normalized Difference Vegetation Index). Figure (1) shows the surface temperature over the country and Figure (2) is the vegetation cover.

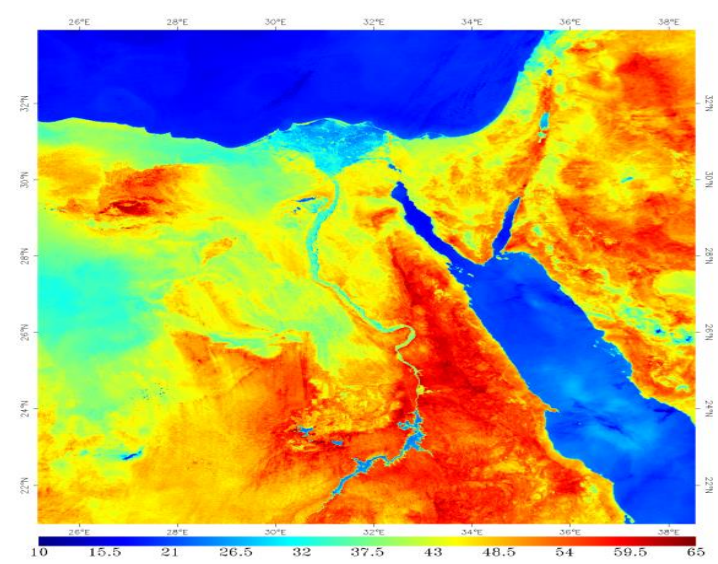

Figure 1. Operational daily sea surface temperature

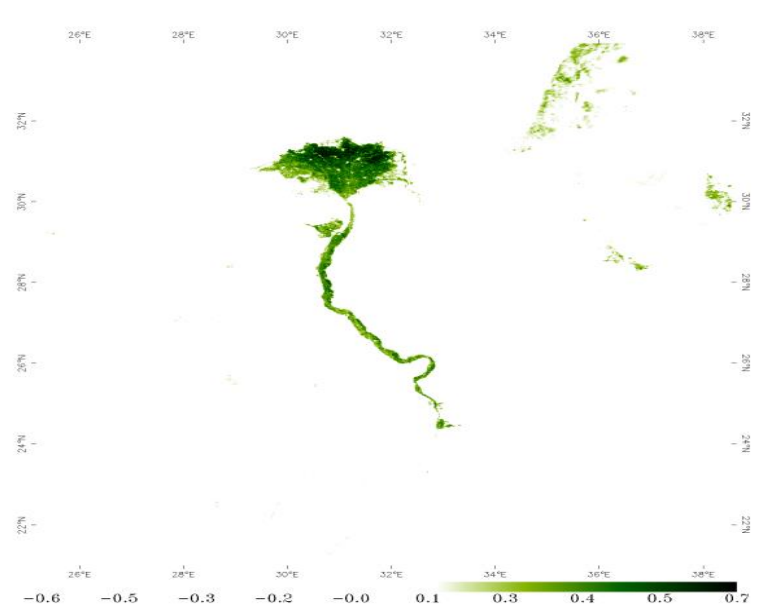

Figure 2 operational daily NDVI

\section{PROJECTS THAT CONTRIBUTE TO THE EGYPT 2030 SDGS}

In correspondence to the priority areas set by the Egyptian government for achieving the national SDGs by 2030 via mega projects and strategic projects, this section will provide some applications in these fields and how much remotely sensed data and geospatial information could provide solution in this area. It will also provide highlight on the new remote sensing technologies and research trends in remote sensing application in this field.

\subsection{Agriculture and Food Security}

To ensure high level of sustainable agriculture use to secure food for the local community, there is a need to sustainably use the land, and water to increase the efficiency of productivity. Remote sensing tool is an efficient source of information that enables to study the agriculture sector in different ways: 


\section{A) Monitoring national crops}

Food security is one of the global and national challenges that grasp great attention from decision makers and community. In Egypt, limited area ( $\cong 5 \%$ of the total Egyptian territory) is described to be agricultural land where also the highest population densities are located. Most of the Egyptian agricultural land is located in Nile Delta and the flood plain of the river Nile due to the fertile land. However, major threat of urban encroachment on this fertile land is recently grown up. Also, land degradation and soil salinization become a major threat on the northern coastal zone of the Nile Delta. One of the major applications of remote sensing applications in the Nile Delta and Flood Plain of the Rive Nile is to monitor the national crops such as rice belt zone. Remote sensing was effectively used to monitor the rice belt zone in the Nile Delta and estimate the actual rice plantation zone which estimated at $11977 \mathrm{Km}^{2}$ (Afify et al., 2010). Figure (3) shows the actual rice plantation zone in the Nile Delta in 2010 estimated from the Egyptsat- 1 satellite images. Since that time an operational system for regular monitoring of rice crop using remotely sensed data is functioned. The system is not only to monitor the crop area, but also to estimate the crop yield based on retrieving the biophysical parameters from the satellite images (e.g. EgyptSat-1, SPOT) (Noureldin et al. 2013). Multi-regression model between the biophysical parameters (i.e. LAI, NDVI) found to be efficient to estimate the rice yield at nearly $\mathrm{r}^{2}$ of 0.85 . This was important information for decision makers to forecast the deficit of the societal needs of rice and plan early ahead for importing the required quantity. The same system was applied for other national essential crops like wheat.

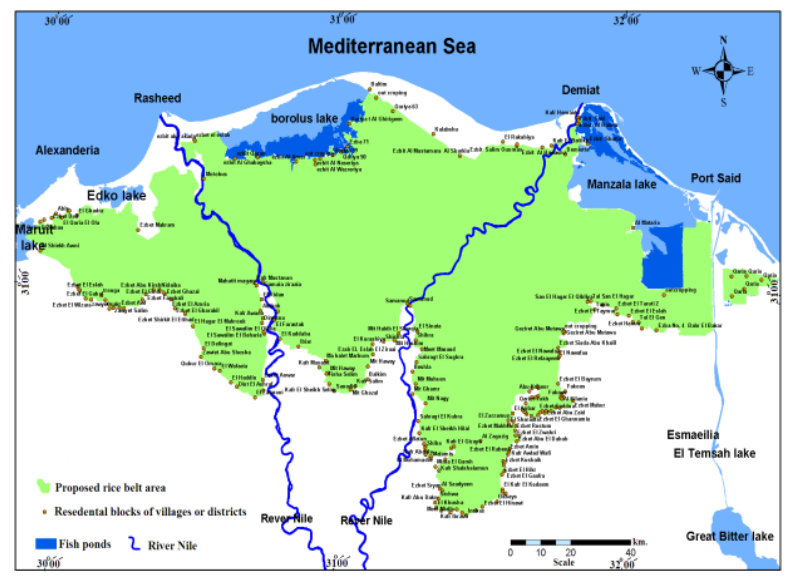

Figure 3. Rice crop zone in the Nile Delta (After: Afify et al., 2010)

\section{B) Urban encroachment and the loss of agricultural land}

Urban settlements are one of the well identified categories of land use (Sabins, 1997). Remotely sensed data offers frequent real-time information which is very efficient in land use discrimination. Improved techniques and modelling have greatly improved the performance of remote sensing classification; however there is still considerable scope for improvement (El-Magd and Tanton 2003). The Nile Delta and the flood plain are the occupied land by Egyptian population for agriculture, residential and economical activities. Unfortunately, one of the most serious threats of man-made is the urban growth on the fertile land of the Nile Delta and the flood plain. This phenomenon has been increased at a dangerous rate after 2011 revolution till 2014. There is various rate of increase along the time dimension to accommodate the population grow.

To operationally monitor the urban growth in the Nile Delta and flood plain of the River Nile, many studies and research projects have been applied to provide baseline information on the rate of growth and losses of the fertile land. For example urban growth in big cities of Menofya governorate in 100 years from 1910 to 2010 showed enormous increase reaching 12 times of the initial built up area (Abou El-Magd et al., 2015). Figure (4) shows the urban growth in these cities in the last century.

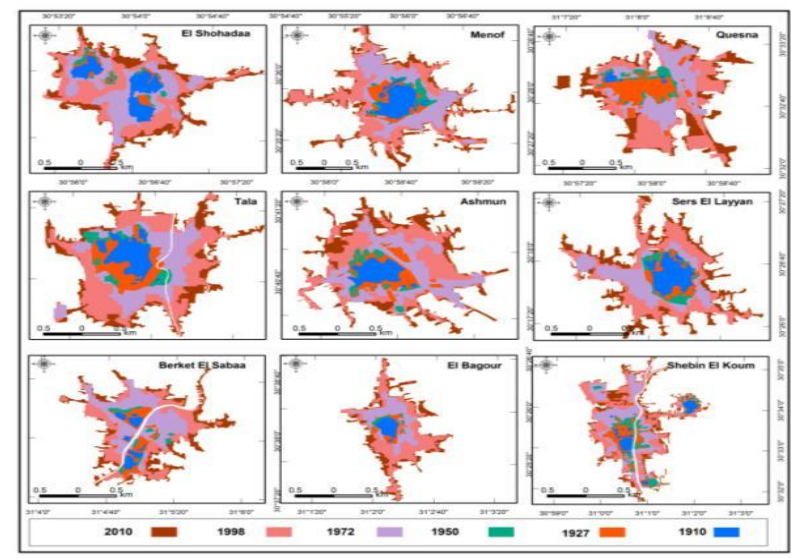

Figure 4. Urban growth rate in the heart of the Nile Delta in 100 years from 1910-2010 using remotely sensed data

\subsection{Coastal and Marine Environment}

Coastal zones are widely exploited and heavily populated in many zones of the world. It attracts population density and development due to the wealth of natural resources such as fresh water, flat fertile soils, recreation places, mineral resources, and fish farming opportunities. This wealth of natural resources in the coastal area attracts individuals and governmental and non-governmental entities to establish various development projects (Abou El-Magd and Hermas, 2010). Egypt has more than $3000 \mathrm{Km}$ length of coastal zone on the Mediterranean Sea, Red sea and both Gulf of Suez and Aqaba. In the vision 2030 for Egypt, the coastal zone was targeted in many mega projects (Suez Canal logistics) and strategic projects in the mining and development in the North Western coastal zone and the Golden Triangle.

Many research and studies used remote sensing and spatial modelling was used for the coastal zone development. Each coastal zone region is more suitable for specific kind of development and activities. The area between Port Saeid and Alexandria on the Mediterranean coast is highly flourished 
with fish farming. Satellite data was used to monitor the increase of fish farms in the last two decades. Nearly 856 $\mathrm{km} 2$ were developed as fish farms in the last 25 years (Ali and El-Magd, 2016). Figure (5) is a high resolution satellite image that shows the fish farms and aquaculture activities in El-Deiba Triangle north Lake Manzala. Such regular high resolution satellite images enable to map and quantify the growth of the fish farms and provide regular updates on the aquaculture development. This enabled to develop a decision making tool to estimating the yield and fish stock that satisfy the local needs or the plans for export.

It is also recommended other suitable areas for fish farming due to the salinity and the closing to the sea for water supply. This has challenged the government to establish a large aquaculture project near Baltim city.

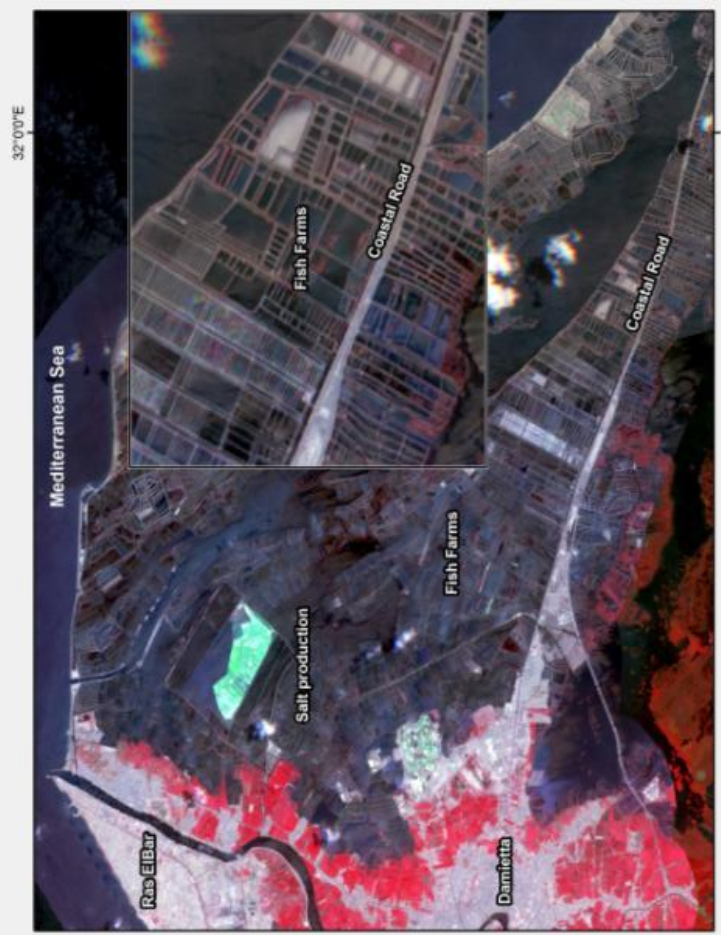

Figure 5. The monitoring of fish farms in the north coastal zone of Lake Manzala (El Deiba Triangle)

\subsection{Monitoring ecosystems}

Red Sea is wealthy marine environment of coral reefs that play key role in the touristic activities and supporting the local economy. The interaction between human activities with the coral reefs together with natural implications of climate changes or/and hazards cerates major threat on these resources. Remote sensing found to be a powerful source of real time information to monitor the environmental changes and detect the deterioration of coral reefs. It is, however, requires field checks and validation particularly in areas like Hurgadah where there is a fluctuation of the tide that mislead the reflectance of the remotely sensed dataMulti-dates of satellite images always used to monitor and estimate the rate of changes of the coral reef in the Red sea coast and estimate the rate of damage and deterioration of the coral reefs. Figur (6) shows a vulnerability map of the coral reef at Hurghada that shows high rate of deterioration reached to $64 \%$ in the last two decades.

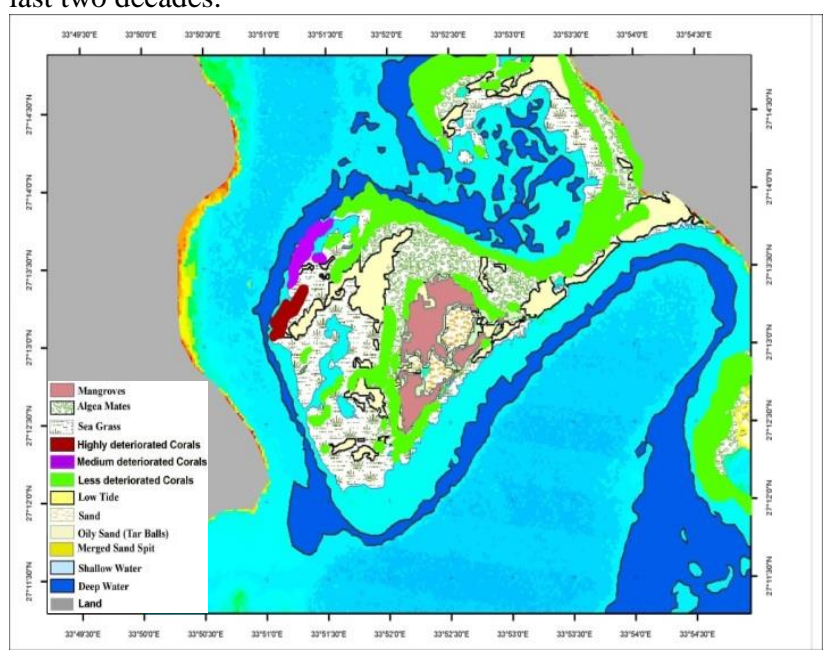

Figure 6. Vulnerability map of coral reefs at Abu Monqar Island, Red Sea Coast (After: Ahmed Et al., 2009)

\subsection{Explore mineral resources and mining activities}

The strategic project of development of the Golden Triangle in the eastern desert is one of the major priorities in Egypt to foster economy. Essential component in the development of this area is the exploration of mineral resources. For example, gold's value was the main driving force behind most of the mining activities. Historically, nearly 95 known localities of gold mineralization spread over almost the entire Eastern Desert of Egypt covered by the crystalline basement rocks with the exception of the extreme northern part, where the Pharaonic miners extracted gold from the Precambrian bedrock (e.g. Sukari, Barramiya, El-Sid and others) (Sabet and Bordonosov, 1984).

Recently NARSS has focused on using remotely sensed data and other in-situ measurements for mineral exploration. Figure ( 7 is an example of functioning spectral band ratio of ASTR satellite image to map the potential areas of alteration zones for gold metal. Since the alteration zones are driven by the thermal solutions leakage from the earth, superimpose of the lineaments or/and geological fractures could improve the precise location of alteration zones. The purple circles show the highest potential areas for gold metal, which was validated against the location of the old mines (green dots). Similar researches are applied on other different mineral resources such as iron and ornamental stones. 


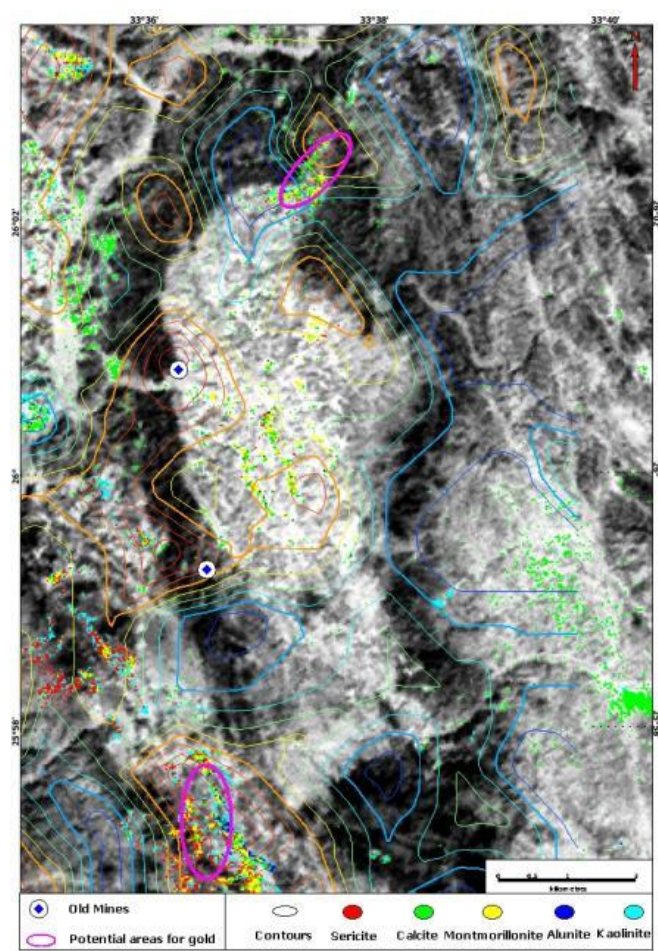

Figure 7. Potentiality of alteration zones for gold mine in Eastern Desert (After: Abou El-Magd et al., 2015)

\section{FUTURE PERSPECTIVE /STRATEGIC ROADMAP}

NARSS is looking forward strengthen the capacity in the new technologies of remote sensing such as Radar technology and LiDAR. Radar is in use to operational creating soil moisture map of the country (figure 8- example for some areas in Sinai) and LiDAR for 3-D cities (figure 9- example of the Pyramids).

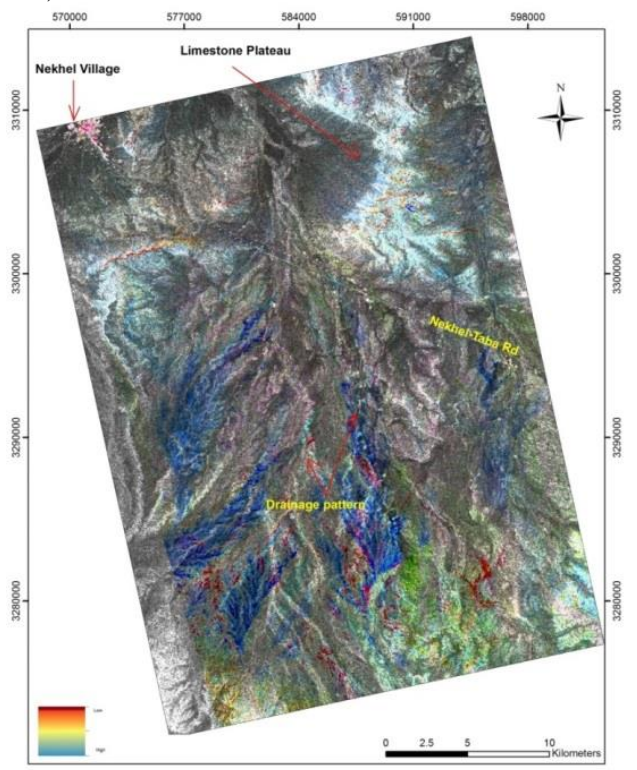

Figure 8. Example of soil moisture content from radar data

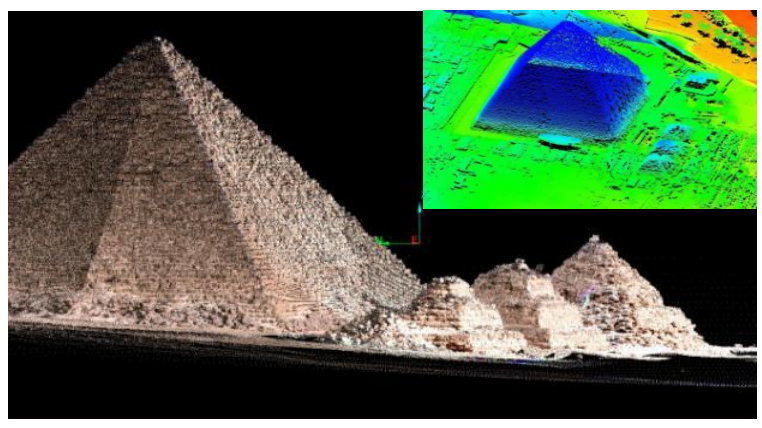

Figure 9. Example of LIDAR 3-D mapping of Pyramids

\section{CONCLUSION}

It could be concluded that remote sensing is an effective tool for societal benefits and contributing to achieving the SDGs. Egypt in its vision for 2030 SDGs agenda is showing great attention to improve the economic and social status via mega projects and strategic projects. Unless, there is reliable and precise information the implementation of these projects will be under threat. For example, the development of the 1 million acre for agriculture, unless there is accurate information about the soil and land suitability as well as the availability of water this project could be not realistic for implementation. This why, the global SDGs called for the benefit from the earth observation data to ensure high level of accuracy and reliability. Further in-situ equipment's are necessary such as ground penetration radar (GPR) to compliment with remote sensing and gravity data to study the ground water reservoir.

Satellite data provided routine daily information of the status of the earth, when modelled could estimate valuable information that could not be easily obtained on-site. The improved research models are important to allow of obtaining direct information from the satellite images. For example, the ratio of spectral bands could map and determine the potential areas for mineral resources or could estimate the yield of a specific crop. Furthermore, the routine eye on the earth from satellite data could help monitor the urban growth on the fertile land of the Nile Delta and flood plain of the Nile River. So, the real time information from satellites is of great importance for planners and decision makers. It is important the government realize the importance of this source of information to use in the implementation of the mega projects and strategic projects. Finally, Egypt is using these technologies to ensure high level of achieving the development goals, strengthen its capacity with the region in this field and contribute to the global arena.

\section{REFERENCES}

Abou El-Magd, I., Mohy, H. and Basta, F., 2015. Newly Improved Band Ratio of ASTER Data for Lithological Mapping of the Fawakhir Area, Central Eastern Desert, 
Egypt, International journal of the Indian society of remote sensing, DOI 10.1007/s12524-015-0539-0.

Abou El-Magd, I., Hermas, E.A., 2010. Human Impact On The Coastal Landforms In The Area Between Gamasa And Kitchner Drains, Northern Nile Delta, Egypt, Journal of Coastal Research,26(3), pp. $541-548$.

Abou El-Magd, I., Hasan, A., ElSayed, A., 2015. A Century of Urban Sprawl in Menofya Governorate, Egypt, Using Remote Sensing and Geographic Information Analysis, Journal of Geographic Information System, 7, pp. 402-414.

Afifya, A.A., Arafatb, S.S., Aboel Gharb, M., Khadera, M.H., 2010. Physiographic soil map delineation for the Nile alluvium and desert outskirts in middle Egypt using remote sensing data of EgyptSat-1, The Egyptian Journal of Remote Sensing and Space Science, 13(2), pp. 129-135.

Ahmed, M.H., Ali, E.M., Abou El-Magd, I., 2009. Detection of temporal changes in coral reefs at Hurghada (Red Sea, Egypt) and environmental factors controlling deteriorated sites using landsat and field data. Egyptian Journal of Aquatic Biology and Fisheries, 13(4), pp. 403-419.

Ali, E.M., Abou El-Magd, I., 2016. Impact of Human Interventions and Coastal Processes along the Nile Delta
Coast, Egypt from the Past Twenty-Five Years, Egyptian Journal of Aquatic Research, 42, pp. 1-10.

El-Magd, I. A., Tanton, T., 2003. Improvements in Land Use Mapping for Irrigated Agriculture from satellite Data Using a Multi Stage Maximum Likelihood Classification, International Journal of Remote Sensing, 24(21), pp. 41974206.

Ministry of International Cooperation., 2016. Arab Republic of Egypt National Review Sustainable Development Goals, Ministry of International cooperation, pp. 112.

Noureldin, N.A., Aboelghar, M.A., Saudy, H.S., Ali, A.M., 2013. Rice yield forecasting models using satellite imagery in Egypt, The Egyptian Journal of Remote Sensing and Space Sciences, 16, pp. 125-131.

Sabet, A.H., Bordonosov, V.P., 1984. The gold ore formations in the Eastern Desert of Egypt. Annals of Geol. Survey, Egypt, 16, pp. 35-42.

Sabins, F.F., 1997. Remote Sensing Principles and Interpretation. W. H. Freeman and Company, New York. 